\title{
Analytical Comparision between Single and Modular Fuel Cell Stack: Uniform Modular Cell Approch
}

\author{
Megavath Venkatesh Naik, Paulson Samuel \\ Departement of Electrical Engineering, Motilal Nehru National Institute of thechnology Allahabad, Allahabad, India
}

\begin{tabular}{l} 
Article Info \\
\hline Article history: \\
Received Apr 8, 2017 \\
Revised May 13, 2017 \\
Accepted May 20, 2017 \\
\hline Keyword: \\
Maxium power tracking \\
Modular structure \\
Non uniformity in fuel \\
cells \\
Underperforming fuel \\
cells
\end{tabular}

\section{Corresponding Author:}

\section{M.Venkatesh Naik}

Departement of Electrical Engineering,

Motilal Nehru National Institute of Technology Allahabad,

Teliarganj, Allahabad-211004, Uttar Pradesh, India.

Email: venkateshn@mnnit.ac.in

\begin{abstract}
A single fuel cell (FC) produces a very small voltage of about $0.6-0.8 \mathrm{~V}$ under normal operating condition, and hence several individual cells are connected in series as a stack to get higher voltages suitable for practical loads. The stacks are then connected in series to get required values of DC voltage. The FC performance varies with the operating parameters such as temperature, humidity, fuel flow rate, ageing and fuel non uniform concentration. The FC stack underperforms when there is presence of bad cell in it. The Presence bad cell in a stack limits the current handling capacity of other healthy cells when it's connected as a conventional single stack. This can be overcome by connecting the fuel cells in uniform modular cell configuration. In this paper a Uniform Modular Cell Configuration (UMCC) is proposed to gain the maximum power from the stack and the conventional Single or Uni Stack Configuration (USC) is compared with the proposed structure. A detail mathematical analysis of comparing both methods is described. Further the superiority of the proposed method is proven by carrirying out the simulations under steady state operating condition of a FC stack feeding to a constant current load.
\end{abstract}

Copyright $\odot 2017$ Institute of Advanced Engineering and Science. All rights reserved.

\section{INTRODUCTION}

Fuel cell (FC) is a device which produces electrical energy by processing the chemical reactions of Hydrozen (H2) and Oxyzen (O2). The only by product is the clean water (H2O) as shown in Figure.1. The voltage produced by the process of chemical reaction varies with the load and ranges from $0.4 \mathrm{~V}-0.8 \mathrm{~V}$ on full load to no load respectively for a single cell. There are almost 1:2 variations in the FC output voltage [1]. The individual cells are connected together to form a stack and to get the higher voltages inorder to be of practical use .Further the stacks are connected again in series to obtain the required voltages based on the application[2]-[4]. As the fuel cell power sources (FCPS) are emrging technologies and incurs higher expendiute on development and entails high running cost. Therefore, to get the best outcome on the investement, it's necessary to extract the Maximum power from FCPS under all operating conditions. The output voltage of the typical FC has non linear relationship with the load current (as illustrated in Figure 2)and also with some operating parameters such as temperatue, fuel and oxidant flow rates, humidity and aging etc [5]. 


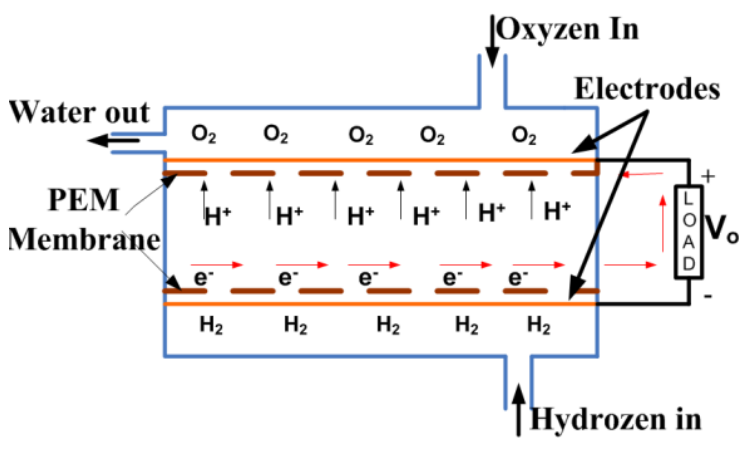

Figure 1. PEM Fuel Cell Connected to DC Load



Figure 2. VI and PI Characteristics of PEM Fuel Cell

The FCPS are generally of high current and low voltage devices.Usauuly they are connected in series to get the suitable higher voltage for a particular application.However, there is a practical limitation of connecting number of series cells in a stack.Incresed number of cells in a stack introduces the difficulties like sharing the fuel pressure, non uniform reactant concentration and humidity in each cell [6]. When one of the series connected cells in a stack is underperforming the current delivered by that particular cell is limited by the current handling capacity of it. This situation arises to forcefully limit the current of a healthy cell and there by the power output of the stack decreases. A significant research has been carried out on extracting maximum power from the FCPS [5]-[13]. Recursive estimation of tracking maxium power is has been presented in [5]. A new adaptive extremum scheme of MPPT and some MPPT schemes are have been presented in [6].The MPPT by P\&O and fuzzy logic controller methods are elaborated in [7] and [8], and these methods are compared in [9] with respect to the speed, design and complexity terms. In [10] extremum seeking algorithm has been discussed. MPPT based on internal resistance is discussed in [11] and the method of controlling concentration losses are descrbed in [12]. The adaptive control approach to gain maximum efficiency is proposed in [13]. The method of current compensation technique to extract the maximum power has been proposed by B. Somaiah et al [14]. A modular apporch for gaining the maximum power has been proposed in [15] and [16].In this modular scheme a single FC stack is divided into suitable number of sections and each section delivers power to the load.

In this paper, mainly it's concentrated on the comparative analysis of modular structure and single stack configurations. For the purpose of the study the modular structure is defined as uniform modular cell structure (UMCC) and single stack configuration is defined as uni stack configuration (USC). In USC case the total number of cells considered as ' $n$ ' and in UMCC the ' $n$ ' no. of total cells in a stack are divided into $\mathrm{k}$ modules with ' $\mathrm{n} / \mathrm{k}$ ' cells in each module, i.e. the cells are uniformly distributed in each module, and individual modules supplies power to the load.The underperoformance of the stack is realized by changing ohmic resistance of the FC stack form its normal value. Futher the power supplied by the USC and UMCC are compared and proved that the later supplies higher power to the load. This paper contains four sections, Section II of the paper discusses the mathematical derivations of voltage, current and power of USC and UMCC approaches using maximum power transfer theorem. Also the mathematical analysis for ' $\mathrm{m}$ ' no. of cells in an underperforming stack or module has been done. In section III simulation results to show the benefit of the proposed approach when compared to the conventional uni stack model has been presented. In section IV conclusion of the electrical performances of two configurations are presented and the superiority of UMCC demonstrated.

\section{MATHEMATICAL MODELLING OF THE PROPOSED METHOD}

The voltage produced by a cell in a stack ranges from $0.8 \mathrm{~V}$ at No-load to $0.4 \mathrm{~V}$ at full load. As the cell voltage is low, they are connected in series to form a stack. Suppose 'n' numbers of cells are to be used in order to make a single FC stack. In this paper the following two configurations are analyzed and compared with FC stack voltages, currents and power supplied to a DC load under rated operating condition.

The two configurations taken into consideration are

a. Uni stack configuration (USC).

b. Uniform modular cell configuration (UMCC). 


\subsection{UNI STACK CONFIGURATION (USC)}

Suppose all the $\mathrm{n}$ cells are connected in series to form a single stack as shown in Figure 3 (a). The stack voltage is summation of all individual cell voltages.

$$
V_{F C S}=V_{C 1}+V_{C 2}+\cdots \ldots \ldots \ldots \ldots+V_{C n}
$$

If all the cells in a stack are healthy, then

$$
\begin{aligned}
& V_{C}=V_{C 1}=V_{C 2}=\cdots V_{C n} \\
& R_{C}=R_{C 1}=R_{C 2}=\cdots R_{C n}
\end{aligned}
$$

Where " $V_{C}$ " is the voltage produced by single cell and " $R_{C}$ " is the internal resistance of single fuel cell due to membrane, ohmic, anode and cathode. " $\mathrm{V}_{\mathrm{FCS}}$ " is the voltage produced by FC stack of $\mathrm{n}$ cells and " $\mathrm{R}_{\mathrm{FCS}}$ " is the sum of internal resistances of cells of stack.

When all the cells are healthy the stack voltage is given by

$$
V_{F C S}=n \times V_{C}
$$

Accordingly

$$
R_{F C S}=n \times R_{C}
$$

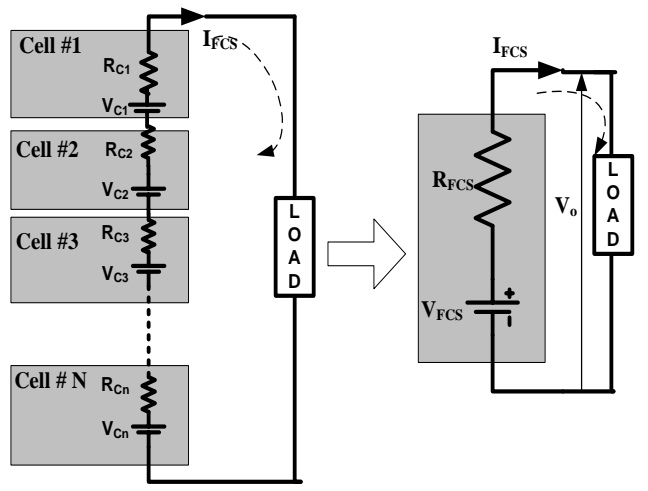

Figure 3. a) Equivalent Circuit of USC Case with n Cells b) Equivalent Circuit of 3(a)

According to circuit theory, to extract the maximum power the source resistance and load resistances are equal.

$$
P_{\max }=\frac{V_{F C S}^{2}}{4 R_{F C S}}
$$

Also the output power delivered by the FC Stack is given by

$$
P_{0}=V_{F C S}-I_{F C S}^{2} R_{F C S}=n\left(V_{C} I_{F C S}-I_{F C S}^{2} R_{C}\right)
$$

From (4) and (5), its perceptible that increasing the FC stack load beyond the point given by (4) results in increased power losses and shrink in output power, Thus, the load current should be limited to the value given by

$$
I_{F C S, \max }=\frac{V_{F C S}}{2 \times R_{F C S}}
$$


Further, the output voltage of the stack as shown in Figure. 3.(b)

$$
\begin{aligned}
& V_{0}=V_{F C S}-I_{F C S} R_{F C S} \\
& V_{0}=n\left[V_{C}-I_{F C S} R_{C}\right]
\end{aligned}
$$

On comparing (5) and (7) it's known that the power output of the stack is

$$
P_{o}=V_{o} I_{F C S}
$$

Further, in a single stack configuration all the cells are connected in series, hence the load current is limited to the value which the weakest cell can handle or supply, it means the healthy cell which can handle the normal rated current now limited to weakest cell current. By considering this fact the maximum power output of the stack is given by

$$
P_{\text {max }}=\sum_{n=1}^{N} V_{C n} I_{F C S, \max }-R_{C n} I_{F C S, \max }^{2}
$$

There will be mismatch in the electrical performance of the stack when there is a change in operating parameters such as temperature, pressure of the fuel, catalyst concentration, ageing and humidity of the cell. the mismatch leads to underperfomance of the cells in stack. The underperforming cell voltage, current and its resistance is analysed as follows If Cell $\mathrm{I}$ is under performing with voltage $\mathrm{V}_{\mathrm{C} 1, U}<\mathrm{V}_{\mathrm{C} 1}$ and current handling capacity of the same is taken as $\mathrm{xI}_{\mathrm{FCS}}$ where $\mathrm{x}<1$, here ' 1 ' is corresponding to normal value. So the resistance of the underperforming cell is given by the expression

$$
R_{c 1, U}=\frac{V_{C 1}}{x I_{F C S}}
$$

As the cell is weaker the internal impedance of it will be increased as the current through it is reduced by ' $x$ ' times where ' $x$ ' is the current limiting factor defined as the ratio between cell voltage of underperforming and the resistance of the same cell. Now the voltage of stack after excluding the underperforming cell is given by

$$
V_{0}=(n-1)\left\{V_{C}-x I_{F C S} R_{C}\right\}+V_{C 1, U}-x I_{F C S} R_{C 1, U}
$$

The power output of the stack will be reduced to the value given by

$$
P_{o}=V_{0}\left(x I_{F C S}\right)
$$

As all the cells are connected in series, if even one cell among several cells in a stack is underperforming, the other healthy cells also have to forcefully carry the current supplied by underperforming cell. It means the utilisations of the healthy cells are very poor in the case of single stack configuration.

Similarly If ' $m$ ' No. of cells in a stack are underperforming $(\mathrm{m}<\mathrm{n})$, with voltages and currents values lesser than the rated values. Let $p^{\text {th }}$ cell is weakest among ' $\mathrm{m}$ ' underperforming cells. Then the current supplied by the weakest cell will be equal to $x_{p} I_{F C S}$.

Output voltage of the stack under this situation is given by

$$
V_{o}=(n-m)\left\{V_{C}-x_{p} I_{F C S} R_{C}\right\}+\sum_{\square=1}^{m}\left(V_{c i}-x_{p} I_{F C S} R_{C i}\right)
$$

he output power of the stack when these is a weakest cell among the ' $\mathrm{m}$ ' No. of underperforming cell is given by

$$
P_{o}=V_{o} x_{p} I_{F C S}
$$

It can seen from the above analysis that the healthier cells have a smaller internal resistances and larger open circuit voltage, hence can supply higher load currents (133.33A).From the above analysis it is clear that the presense of a single bad cell in a stack can affect the overall power suppled by the stack. This problem can be overcome by using modular structure [14] and their analyses are elaborated in the next section.

IJAAS Vol. 6, No. 1, March 2017: 89 - 97 


\subsection{UNIFORM MODULAR CELL CONFIGURATION (UMCC)}

The effect of presenting underperforming cell in a stack can be reduced by applying modular structure i.e UMCC approach as shown in Figure.4 In this scheme a single stack with $\mathrm{n}$ cells which is discussed in the previous section, now it is divided into ' $\mathrm{k}$ ' modules and each module has $\mathrm{n} / \mathrm{k}$ cells. From Figure .4 it's seen that each FC module terminals are connected to an individual load. By doing so, the presence of bad cell in a module can not affect the other healthy cells of remaining modules.Hence they can supply their rated power to the load always. For soppose, if a weakest cell is presented in module 1, then the current supplied by the module 1 is only affected and the reduced power is sent to the concerned load 1 . The other helathier modules can supply maximum power to the corresponding loads. Here it is assumed that the generated voltage by a single cell in a module is $V_{c}$, the current supplied by the cell is $\mathrm{I}_{\mathrm{fc}}$ and resistance of a cell is $\mathrm{R}_{\mathrm{C}}$.the current supplied by the module $1,2,3-----\mathrm{k}$ are Is 1 , Is 2 , Is3,------Isk respectively. Output voltage of Module 1, can be written as

$$
V_{o 1}=\frac{n}{k}\left[V_{C}-I_{s 1} R_{C}\right]
$$

Also the output voltage of the Module 2 is given by

$$
V_{o 2}=\frac{n}{k}\left[V_{C}-I_{s 2} R_{C}\right]
$$

Accordingly the output voltage for $k^{t h}$ module is written as

$$
V_{o k}=\frac{n}{k}\left[V_{C}-I_{s k} R_{C}\right]
$$

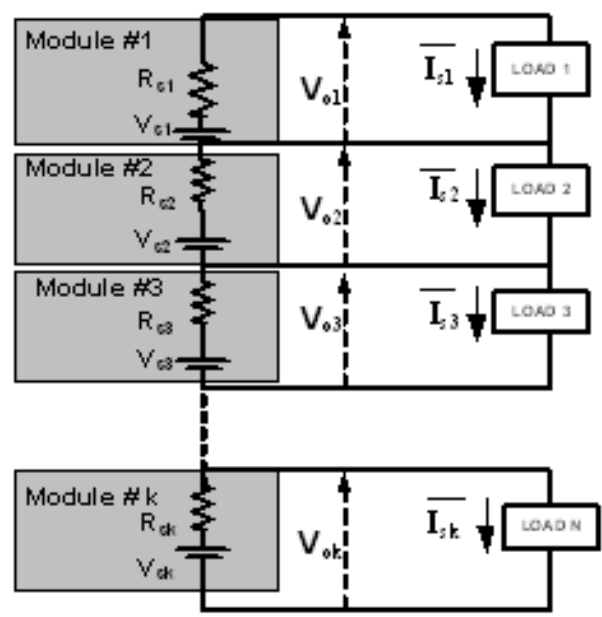

Figure.4 Equivalent Circuit of UMCC with $n / k$ Cells in Each Module.

The total output voltage available in the UMCC is $\sum_{i=1}^{k} V_{o i}$, and the total power supplied by the stack sum of power supplied by k modules.

$$
P_{o}=\sum_{i=1}^{k} V_{o i} I_{s i}
$$

The maximum power generated by each module of the stack is calculated as

$$
P_{\max }=\sum_{i=1}^{k} \frac{V_{S i}^{2}}{4 \times R_{S}}
$$

From (9) and (19) it is apparent that the maximum power supplied by the UMCC approch is more than USC case. However, it is not possible to say in which module the bad cell is presented. The analysis of presence of bade cell in one or many modules are described as follows. If one single cell among ' $\mathrm{n} / \mathrm{k}$ ' cells of 
module \#1 is underperforming with current $x I_{f c}$, voltage $v_{c 1}$ and resistance $R_{c 1}$. Where $x<1, v_{c 1}<v_{c}$ and cell resistance $R_{c 1}=\frac{\square_{c 1}}{x_{f} f}$ is different than the other cells.Output voltage of the module \#1 is given by

$$
V_{01, U}=\frac{1}{k}\left[(n-1)\left(V_{c}-x I_{f c} R_{c}\right)+V_{c 1}-x I_{f c} R_{c 1}\right] \text { or } V_{s 1}-I_{s 1} R_{s 1}
$$

Output power delivered by the module \#1 is

$$
P_{o 1, U}=V_{o 1} x I_{f c}
$$

So here it is clear that output voltage and current of first stack is reduced.

Output voltage of module \#2 is given by

$$
V_{02}=\frac{n}{k}\left[V_{c}-I_{f c} R_{c}\right]
$$

Output power of the second stack is given by

$$
P_{o 2}=V_{o 2} I_{s 2}
$$

Accordingly for $k^{t h}$ module the output voltage is given by

$$
V_{o k}=\frac{n}{k}\left[V_{c}-I_{f c} R_{c}\right]
$$

The output power for the $k^{t h}$ module is given by

$$
P_{o k}=V_{o k} I_{f c}
$$

It is clear form (22), (23), (24), and (25) that the healthier cells are fully utilized. The maximum power delivered to the load during the UMCC case is greater than the USC case.Further, If ' $\mathrm{m}$ ' cells among any of $\mathrm{k}$ modules $(\mathrm{m}<(\mathrm{n} / \mathrm{k}))$, for example module \#1 is under performing, then let us assume that the output voltages of the underperforming cells are given by $v_{c 1}, v_{c 2}, v_{c 3}, \ldots v_{c m}$ and currents are given by $x_{1} I_{f c}$, $x_{2} I_{f c}, \ldots . x_{m} I_{f c}$. All the currents of underperforming cells are less than rated value i.e. the all multipliers are less than one. The output voltage of module \#1 is given by

$$
V_{o 1, U}=\frac{1}{k}\left[(n-m)\left(V_{c}-x_{p} I_{f c} R_{c}\right)+\sum_{i=1}^{m} V_{c i}-x_{p} I_{f c} R_{c i}\right]
$$

Where $x_{p} I_{f c}$ is current supplied by the weakest cell and $R_{c i}$ is the internal resistance of $i^{t h}$ cell. Accordingly the output power of the module \#1 during underperforming case is given by

$$
P_{o 1, U}=V_{o 1, U} x_{p} I_{f c}
$$

For the module \#2 the voltage and current are given by

$$
\begin{aligned}
& V_{02}=\frac{n}{k}\left[V_{c}-I_{f c} R_{c}\right] \\
& P_{o 2}=V_{o 2} I_{f c}
\end{aligned}
$$

Accordingly the voltage and power for module \#k are written as

$$
\left.\begin{array}{l}
V_{0 k}=\frac{n}{k}\left[V_{c}-I_{f c} R_{c}\right] \\
P_{o k}=V_{o k} I_{f c}
\end{array}\right\}
$$


So the collective output voltage and power from ' $\mathrm{k}$ ' modules are given by

$$
\left.\begin{array}{l}
V_{o}=V_{o 1, U}+V_{o 2}+\cdots+V_{o k} \\
P_{o}=P_{o 1, U}+P_{o 2}+\cdots+P_{o k}
\end{array}\right\}
$$

So it is clear that by connecting the cell in UMCC fashion the maximum power supplied to the load is increased compared to the USC case.

\section{SIMULATION STUDY}

The proposed UMCC approach is analysed by developing proton exchange membrane fuel cell (PEMFC) stack in MATLAB Simulink software tool. The FC fuel flow pressure, air flow rate, and operating temperature are included in the model of PEMFC model. The parameters used in model are presented in Table 1.Here 195(n) similar PEMFCs comprise one single stack and 65(n/k) cells comprises in each uniform modular section. All the cells are identical and for each cell the voltage at $0 \mathrm{~A}$ is $1 \mathrm{~V}$, and $0.6923 \mathrm{~V}$ at full load current of 133.3A. The analysis are carried out for a steady state constant current supply.Primarily, the results obtained with USC case are presented. There are two cases considered healthy stack and underperforming stack. During healthy condition (133.33A) the stack can supply its rated power to the load, during underperforming case (100A) the stack can only supply reduced power to the load.

The healthy stack is modelled with the ohmic resistance of $0.044 \Omega$ and the other underperforming case the same stack is modelled with $0.1732 \Omega$. For both the cases flow rate of hydrogen is kept constant at $50 \mathrm{lpm}$ (litres per minute). The voltages of the stack for a constant load during healthy and underperforming cases are shown in Figure. 4 (a) (here SSC represents Single stack condifration as same as USC), it's observed that during healthy condition the terminal voltage of the FC stack is $135 \mathrm{~V}$ and can supply the current of 133.33 A.where as during underperforming case the terminal voltage drops to $125 \mathrm{~V}$ and the current handling capacity is reduced to $100 \mathrm{~A}$, as shown in Figure 4 (b). As the weakest cell in a stack can handle 100A, the other healthy cells connected in series are restricted to carry 100A and hence the power supplied by the stack is reduced to $12.5 \mathrm{~kW}$ as shown in Figure. 4 (c). One can scrutinize from the Figure 4 (c) that the underperforming stack now supplying only $12.5 \mathrm{~kW}$ where as healthier stack can supply $18 \mathrm{~kW}$ of power. In other words $30.55 \%$ of rated power is not supplied to the load because of a bad cell. The performance parameters under USC case is presented in Table 2.

Table 1. PEMFC Modelling Parameters

\begin{tabular}{cc}
\hline Parameter & Values \\
\hline No. of cells $(\mathrm{n})$ & 195 (USC case-(n)) 65(UMCC case \\
& $,(\mathrm{n} / \mathrm{k}), \mathrm{k}=3)$ \\
Open circuit voltage(Eoc) & $195(\mathrm{USC})$ \\
& $65(\mathrm{UMCC})$ \\
Rated current $\left(\mathrm{I}_{\mathrm{FC}}\right)$ & $133.333 \mathrm{~A}$ \\
Ohmic resistance $\left(\mathrm{R}_{\mathrm{Ohm}}\right)$ & $0.044 \Omega$ \\
$\mathrm{H}_{2}$ supply pressure & 3 bar(USC), 1.5(UMCC) \\
$\mathrm{O}_{2}$ supply pressure & 1 bar (USC), $(\mathrm{UMCC})$ \\
Operating temperature & $65^{\circ} \mathrm{C}$ \\
Faraday constant(F) & $96480 \mathrm{C}$ \\
\hline
\end{tabular}

Table 2. FC Performance Parameters of USC Case

\begin{tabular}{ccccc}
\hline $\begin{array}{c}\boldsymbol{P}_{\text {out }} \\
(\mathrm{kW})\end{array}$ & $\boldsymbol{F C} \cdot \boldsymbol{R}_{\text {ohm }}$ & $\boldsymbol{V}_{\text {out }}$ & $\boldsymbol{I}_{\text {out }}$ & Status \\
$(\Omega)$ & $(\mathrm{V})$ & $(\mathrm{A})$ & \\
\hline 18 & 0.044 & 135 & 133.3 & healthy \\
12.5 & 0.1732 & 125 & 100 & weakest \\
\hline
\end{tabular}




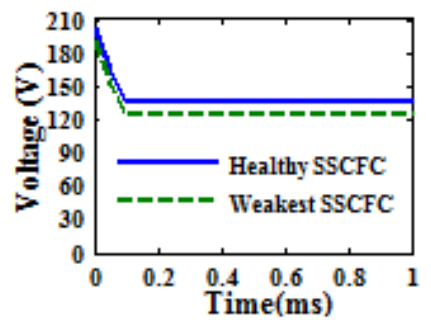

(a)

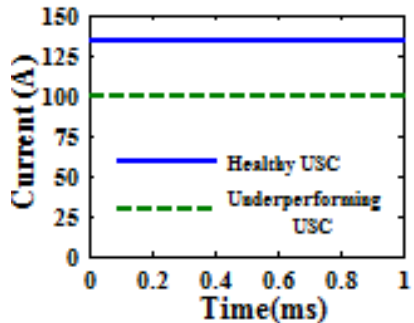

(b)

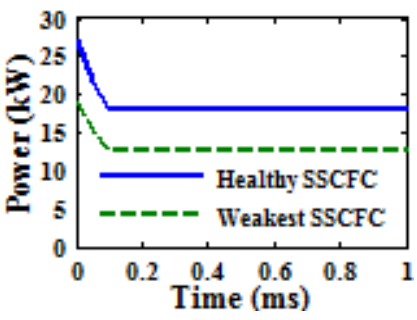

(c)

Figure 4. Mismatch in the Performance of USC Case

a) Stack Voltage b) Current Supplied c) Power Supplied

Where as in UMCC case the power supplied by the FC stack is improved because of its design. Here in this case the stack is devided into three modules $(\mathrm{k}=3)$ named as M1, M2 and M3. Here M1 is considered as healthy module with current carring capacity of $133.33 \mathrm{~A}$ and terminal voltage of $45 \mathrm{~V}, \mathrm{M} 2$ as weaker module with current carring capacity of $120 \mathrm{~A}$ and teminal voltage of $44 \mathrm{~V}$, and M3 as weakest module with current carrying capacity of 100A and terminal voltage of 43V as shown in Figure. 6 (a) and (b).and also the non linear relationaship between modular terminal voltages and FC current at constant fuel supply of $50 \mathrm{lpm}$ is illustrated in Figure 7. The corresponding internal resistances of healthy, weaker and weakest modules are presented in Table 3.

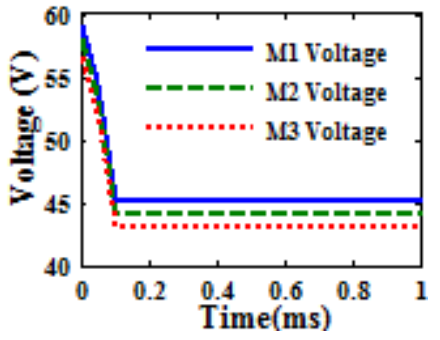

(a)

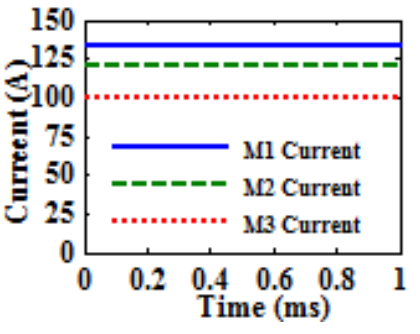

(b)

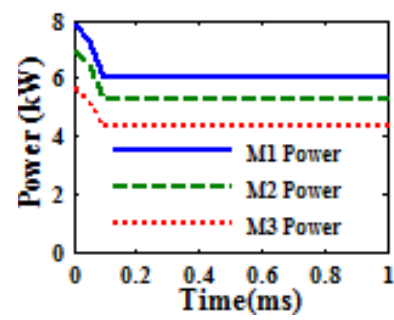

(c)

Figure 6. Mismatch in the Performance of UMCC Case. a) Stack Voltage b) Power Supplied

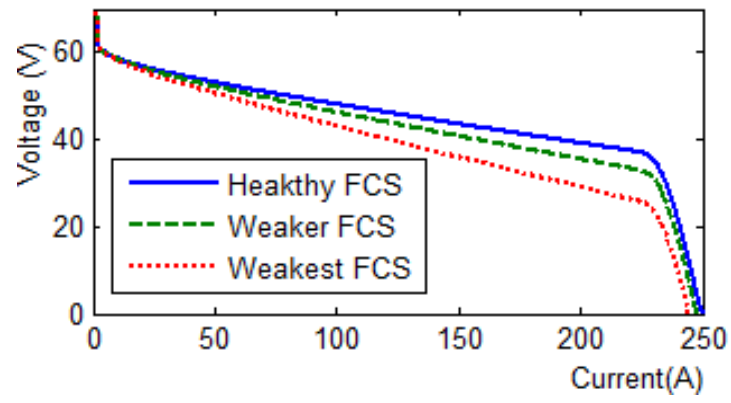

Figure .7 V-I Characteristics of Modular Stack

Table .3 FC performance parameters under UMCC case

\begin{tabular}{cccccc}
\hline $\begin{array}{c}\boldsymbol{P}_{\text {out }} \\
(\mathrm{kW})\end{array}$ & Module & $\begin{array}{c}\boldsymbol{F C} . \boldsymbol{R}_{\text {ohmic }} \\
(\Omega)\end{array}$ & $\begin{array}{c}\boldsymbol{V}_{\text {out }} \\
(\mathrm{V})\end{array}$ & $\begin{array}{c}\boldsymbol{I}_{\text {out }} \\
(\mathrm{A})\end{array}$ & Status \\
\hline 6 & $\mathrm{M}_{1}$ & 0.0783 & 45 & 133.33 & healthy \\
5.28 & $\mathrm{M}_{2}$ & 0.0967 & 44 & 120 & weaker \\
4.3 & $\mathrm{M}_{3}$ & 0.1289 & 43 & 100 & weakest \\
\hline
\end{tabular}


As there is a mismatch in the voltages and currents of the modules of UMCC the powers supplied by them are not same, the same is illustrated in Figure .6 (c), the total collective power supplied by the M1, M2 and M3 is $15.58 \mathrm{~kW}$, where as USC supplies $12.5 \mathrm{~kW}$ for the same weakest condition. The net increment in power supply is $3.08 \mathrm{~kW}$ which is $25 \%$ higher than the USC case. The case study here proves that the modular structure can be applied to supply the maxium available power to the load.

\section{CONCLUSION}

The electrical performance of the series connected fuel cells is non uniform and varies with operating parameters. The underperforming cell becomes the power limiting component for the stack. In this research study, the uniform modular cell configuration is proposed and compared with the existing uni stack configuration. The detail mathematical analyis of both the configurations has been presented and compared with each other. Furthermore, the underperformance of the stack is realized by modelling it with a suitable internal ohmic resistance, for the underperforming cell the ohmic resitance is higher compared to the normal operating cell. The simulation results of USC and UMCC approchches has been carried out for a steady state operating condition. The study has been proved that the UMCC approach enhances by $25 \%$ when compared to the conventional single stack configuration. The UMCC allows to deliver the power individually to the loads from the individual FC modules.However this case is particularly suitable for the basic design but not for any other particular application when working on a stack and also this method best suitable for the high power FC stack in which the number of cells are high.

\section{REFERENCES}

[1] L. Palma and P. Enjeti. A modular fuel cell, modular DC-DC converterconcept.Texas A\& M University, College Station, TAMUS 2431 Invention disclosure.2006.

[2] M. Ellis, M. Spakovsky, and D. Nelson.Fuel cell systems: Efficient, flexible energy conversion for the 21st century. Proc. IEEE. 2001; 89(12); 1808-1818.

[3] Gaurav Sachdeva.Modeling and Simulation of Fuel cell (Dicks-Larminie Model) based 3-Phase Voltage Source Inverter. International Journal of Electrical and Computer Engineering (IJECE.) 2014; 4(5); $691-696$.

[4] Rashmi Sharma.Soft Switched Multi-Output PWM DC-DC Converter. International Journal of Power Electronics and Drive Systems. 2013; 3(3): 328-335.

[5] B. Somaiah and V.Agarwal. Recursive estimation based maximum power extraction technique for a fuel cell power source used in vehicular application. IEEE Trans. Power Electron. 2013; 28(10), 4636-4643.

[6] Z. Zhong, H. Huo, X. Zhu, G. Cao, and Y. Ren. Adaptive maximum power point tracking control of fuel cell power plants," J. Power Sources. 2008; 176(1); 259-269.

[7] M. Dargahi, J. Rouhi, M. Rezanezhad, and M. Shakeri. Maximum power point tracking for fuel cell in FC/battery hybrid systems. In Proc. IEEE Int. Multitopic Conf. 2008; 33-37.

[8] A. M. Latham, P. R. Pilawa, K. M. Odame, and S. C. Rullivan. Analysis and optimization of maximum power point tracking algorithms in the presence of noise," IEEE Trans. Power Electron. 2012; 28(7); 3479- 3494.

[9] T. Esram and P. L. Chapman. Comparison of photovoltaic array maximum power point tracking techniques. IEEE Trans. Energy Convers. 2007; 22(2); 439-449.

[10] G. R. Zhu, K. H. Loo, Y. M. Lai, and C. K. Tse. Quasi-maximum efficiency point tracking for direct methanol fuel cell in DMFC/Super capacitor hybrid energy system," IEEE Trans. Energy Convers 2012; 27(3); 561-571.

[11] A. Giustiniani, G. Petrone, G. Spagnuolo, andM. Vitelli. Low-frequency current oscillations and maximum power point tracking in grid-connected fuel cell based systems. IEEE Trans. Ind. Electron., 2010; 57(6); 2042-2053.

[12] S. Kelouwani, K. Adegnon, K. Agbossou, and Y. Dube. Online system identification and adaptive control for PEM fuel cell maximum efficiency tracking. IEEE Trans. Energy Convers.2012; 27(3); 580-592.

[13] L.Wan L. Palma and P.N. Enjeti.A modular fuel cell. Modular DC-DC converter concept for high performance and enhanced reliability," IEEE Trans.Power Electron. 2009; 24(6); 1437-1443.

[14] Somaiah Boddu, and Vivek Agrawal. Maximum power extraction from series connected fuel cell stacks by current compensation technique.IEEE Trans.Power Electron.2015; 30(2); 582-589.

[15] E. Cengelci, P. Enjeti, and J. W. Gray.A new modular motor-modular inverter concept for medium-voltage adjustable-speed-drive systems. IEEE Trans. Ind. Appl. 2000; 36(3); 786-796.

[16] L. Palma and P. N. Enjeti. A modular fuel cell, modular DC-DC converter concept for high performance and enhanced reliability. IEEE Trans. Power Electron.2009; 24(6); 1437-1443. 